\title{
Importância dos agentes para a arquitetura escolar: aplicação de jogo de apoio ao processo participativo
}

The importance of stakeholders for school architecture: a game to support participatory processes

\section{Marcella Savioli Deliberador Doris Catharine Cornelie Knatz Kowaltowski}

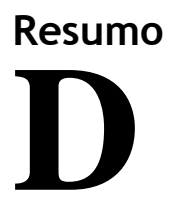

iscutir a melhoria na educação significa trabalhar em uma abordagem multidisciplinar que inclua os diversos agentes, cada um contribuindo em sua área para que sejam repensados os novos modelos educacionais. Os processos de projetos escolares deveriam incluir não só especialistas diversos da área de educação, como também profissionais de projeto, consultores de várias áreas e a comunidade escolar. Para isso, este artigo discute os processos participativos e apresenta uma ferramenta de suporte ao programa arquitetônico aplicada com a metodologia dos grupos focais. Em termos metodológicos, essa pesquisa fundamentou-se em revisão bibliográfica, no desenvolvimento de ferramenta em formato de jogo, nos testes realizados por meio de grupo focal, na elaboração do programa arquitetônico e na avaliação dos resultados. O jogo, definido como um baralho, está dividido em quinze naipes, cada um representando uma temática importante para a arquitetura escolar. A inclusão dos diversos agentes garantiu que as diversas vozes fossem ouvidas e proporcionou um novo olhar sobre o edifício. Entende-se que esse tipo de processo busca o desenvolvimento de meios que visem à ampliação da qualidade do projeto e da educação.

Palavras-chaves: Agentes. Arquitetura escolar. Processo participativo de projeto. Programa arquitetônico. Jogos de apoio.

\begin{abstract}
In order to improve education many steps and actions are necessary. New schools have an impact on society and the buildings need to express environmental, social, technical and economical values. Several different stakeholders should be involved in the discussion of new educational models. The physical environment must be included in the debates and the design process of new schools should include educational specialists, design professionals and the school community. The methodological question here is how to make the participation of such a diverse group of people feasible. This article discusses different stakeholders that should be involved in a participatory design process at the briefing phase. The methodology used in this study is based on a literature review of architectural programming tools and design parameters for school buildings. A game was developed to function as a support tool. A focus group methodology was used to test the tool for briefing. The tool, similar to a deck of cards, is divided into fifteen suites, which represent essential topics related to school architecture. The application of this game structures the debate in the focus group. A simulation of that participatory process is described. The inclusion of the different stakeholders ensured that the different voices were heard and the results show that each stakeholder has his or her individual contribution to the debate. A participatory design process supported by this type of tool can aid in the development of ways to improve the quality of school buildings, as well as the quality of education as a whole by giving support to better learning environments.
\end{abstract}

Recebido em 03/03/17 Aceito em 12/08/17

Marcella Savioli Deliberador Universidade Estadual de Campinas

Doris Catharine Cornelie Knatz

Kowaltowski

Universidade Estadual de Campinas Campinas - SP - Brasil

Keywords: Stakeholders. School architecture. Participatory design process. Briefing. Support games.

DELIBERADOR, M. S.; KOWALTOWSKI, D. C. C. K. Importância dos agentes para a arquitetura escolar: aplicação de jogo 273 de apoio ao processo participativo. Ambiente Construído, Porto Alegre, v. 18, n. 2, p. 273-288, abr./jun. 2018. ISSN 1678-8621 Associação Nacional de Tecnologia do Ambiente Construído. 


\section{Introdução}

Diversas são as abordagens importantes ao se discutir a necessária melhoria na educação, especialmente no caso de países em desenvolvimento como o Brasil. A multidisciplinariedade das propostas deve incluir os diversos agentes em um esforço conjunto, em que cada um contribui para serem pensados novos modelos educacionais para a realidade atual. Isso significa que se deve refletir sobre as importantes questões envolvidas com a educação, tais como as pedagogias, a formação dos professores e outros profissionais da área, bem como a infraestrutura física necessária. Essa última inclui a arquitetura escolar de qualidade.

As pesquisas vêm demonstrando que existe relação entre a qualidade espacial e a capacidade de aprendizado dos alunos (BARRETT et al., 2015). Garantir essa qualidade implica processos de projeto bem estruturados e com o suporte adequado. Esse apoio não depende somente das equipes de profissionais de projeto, mas também de outros agentes. Nesse sentido, deveriam ser incluídos tanto os especialistas diversos da área de educação (pedagogos, psicólogos, sociólogos, representantes dos órgãos governamentais) quanto profissionais de projeto (arquitetos, engenheiros, paisagistas, urbanistas) e consultores de várias áreas (conforto ambiental, sustentabilidade, psicologia ambiental, saúde e segurança), entre outros. A comunidade escolar deveria participar e ser representada por diferentes tipos de alunos, por pais, professores, diretores e outros funcionários, bem como por membros da vizinhança. Existem ainda especificidades de cada local que devem ser incorporadas.

A partir do cenário acima descrito, destaca-se a importância em conduzir processos capazes de incluir esses diversos agentes envolvidos com a comunidade escolar. Desse modo pode-se contribuir para um processo que resulte na proposição de soluções que atinjam o cerne das questões educacionais, mas que também seja adequado às questões atuais, como as ambientais, técnicas, culturais, sociais, entre outras. O mundo da educação está em constante mudança, os espaços escolares apresentam dificuldades em acompanhar tal processo, e sabe-se que no Brasil poucos são os ambientes que tiveram sua natureza física influenciada por novos métodos de ensino. Muitas das avaliações pós-ocupação (APO) indicam diversos tipos de problemas no ambiente escolar, desde questões relacionadas ao conforto até aquelas relativas à adequação dos espaços às atividades realizadas (ELALI, 2002; FUNARI; KOWALTOWSKI, 2005; ORNSTEIN， 2005;
DELIBERADOR， 2010; KOWALTOWSKI, 2011).

Deliberador (2010) apresentou a caracterização dos processos de projeto dos arquitetos que desenvolvem projetos para a Fundação para o Desenvolvimento da Educação (FDE), órgão responsável pela construção e manutenção dos edifícios escolares públicos do Estado de São Paulo. Mesmo partindo da particularidade da FDE, essa caracterização pode refletir a realidade dos processos brasileiros de projetos de escolas públicas, que enfrentam dificuldades similares por todo o país. Os projetos conduzidos pela FDE, ainda que passíveis de críticas, apresentam um padrão de qualidade superior quando comparados aos descritos no panorama nacional. A FDE é uma importante referência de processo de projeto, construção e manutenção de escolas no âmbito nacional. Tal caracterização, realizada a partir de entrevistas com os arquitetos e com a FDE, indicou que um dos problemas está relacionado com o fato de o programa arquitetônico ser rígido, padronizado e com pouco espaço de manipulação para que sejam atendidas demandas específicas de cada projeto.

A falta da participação da comunidade em uma reflexão sobre parâmetros de projeto, considerada essencial à arquitetura escolar de qualidade, foi outra característica destacada na literatura específica e ausente no processo atual (AZEVEDO, 2002; WOOLNER, 2009). Novas metodologias pedagógicas vêm sendo desenvolvidas, e torna-se necessário repensar os espaços da arquitetura escolar, o que também indica a necessária participação da comunidade (DELIBERADOR, 2010; TAYLOR; ENGGASS, 2008). Por outro lado, tal caracterização indicou caminhos interessantes de serem explorados visando à melhoria do ambiente escolar construído. Um deles foi a criação de ferramentas de apoio ao processo de projeto em diversas etapas (DELIBERADOR; KOWALTOWSKI, 2015).

Pensando a realização de um novo projeto escolar, outras questões tornam-se relevantes. A integração entre os diversos agentes deve enriquecer $\mathrm{O}$ processo de projeto, mas, ao mesmo tempo, torna a tarefa de programar as necessidades arquitetônicas ainda mais complexa e desafiante aos profissionais envolvidos. A partir dessa premissa, o objetivo deste artigo é discutir o papel dos agentes em um processo participativo de projeto de arquitetura escolar e demonstrar a importância de estruturação desse processo através de ferramentas de apoio. $\mathrm{O}$ enfoque é demonstrar a importância da participação dos diversos agentes para a construção de um programa arquitetônico que discute e define os 
diversos desafios da arquitetura escolar. Uma ferramenta de apoio é apresentada em forma de jogo. Tal ferramenta aborda as temáticas consideradas essenciais à arquitetura escolar e estrutura o debate no processo participativo.

\section{Metodologia}

Quando se trata de um projeto arquitetônico a ser apropriado por diversas pessoas, como é o caso de edifício escolar, a questão metodológica é como viabilizar a participação efetiva do coletivo (MORGAN, 1997). Nesta pesquisa, as etapas metodológicas abaixo foram seguidas:

(a) análise da literatura, cujos resultados indicaram:

- a importância do programa arquitetônico (fase analítica) para a elaboração do projeto e a relevância do processo participativo como elementos essenciais para o desenvolvimento de um projeto de qualidade;

- a necessidade da aplicação de métodos para a elaboração de programa arquitetônico completo;

- o conteúdo do programa arquitetônico, especificamente em razão da dinâmica da educação que impacta o ambiente escolar e sua configuração espacial; e

- os tipos de agentes que deveriam participar, sua importância na discussão do conteúdo e os métodos que permitem a efetiva colaboração desses agentes.

(b) desenvolvimento de ferramenta de apoio ao debate dos agentes, em forma de jogo;

(c) teste com os agentes, na forma de um grupo focal, para aplicação do jogo;

(d) elaboração do programa arquitetônico a partir das informações obtidas no grupo focal, com o preenchimento de fichas desenvolvidas baseadas no Problem Seeking (PEÑA; PARSHALL, 2012) e disponíveis em Deliberador (2016); e

(e) análise da experiência do grupo focal e do resultado obtido na forma de um programa arquitetônico.

\section{Arquitetura e processo de projeto escolar}

Muitos são os aspectos considerados essenciais para a obtenção de uma arquitetura escolar de qualidade, os quais precisam estar em acordo com as realidades em que serão inseridos, respeitando as peculiaridades inerentes a cada processo. A possibilidade de uma arquitetura de qualidade para a tipologia escolar depende de focar a configuração dos ambientes nos alunos e usuários, sendo as soluções apropriadas a cada faixa etária e geradoras de ambientes seguros, confortáveis, acessíveis, flexíveis e equipados, além de aplicar adequadamente os recursos financeiros disponíveis (LACKNEY, 2000). Muito se discute sobre as tendências pedagógicas e as respostas arquitetônicas a elas oferecidas, o que significa que as soluções propostas devem estar adequadas às atividades previstas no ensino, de acordo com a proposta pedagógica que a escola pretende implantar (HILLE, 2011; KOWALTOWSKI, 2011; WOOLNER, 2010; BARRETT et al., 2015; UCCI et al., 2015).

Os espaços devem ser projetados para que estimulem a curiosidade natural, transformando a arquitetura em uma ferramenta de aprendizado (TAYLOR; ENGGASS, 2008). A bibliografia sobre metodologias pedagógicas sinaliza novos paradigmas que pressupõem maior flexibilidade de uso dos espaços, com presença de maior variedade de configurações (HIGGINS et al., 2005; DEED; LESKO, 2015). Assim, edifícios escolares não podem se resumir a um conjunto de salas de aula, sendo necessário incluir espaços de estudo individuais e em grupo, laboratórios específicos, espaços de convívio diversos, entre outros que possibilitem a experiência de aprendizado em sua plenitude.

As práticas pedagógicas vigentes demandam aprendizados baseados em projetos, ou seja, trabalhos multidisciplinares e integrados, que aliam teoria e prática. Geralmente, apresentam resultados com maquetes, cartazes ou outros meios capazes de divulgar o trabalho desenvolvido em determinado período. Isso exige maior espaço e suporte arquitetônico para os diferentes usos e para as diferentes relações entre professores, alunos, pais e comunidade que se estabelecem no ambiente escolar (TAYLOR; ENGGASS, 2008). A inclusão desses agentes no processo de projeto pode significar melhor adequação dos espaços propostos, de acordo com a necessidade de cada local e de cada comunidade que irá receber o novo edifício escolar.

Com relação ao processo do projeto escolar, não se pode deixar de mencionar a importância do processo de projeto integrado. Esse processo pressupõe algumas características metodológicas, como trabalho multidisciplinar, base consensual de projeto, participação e motivação do cliente, inclusão de especialistas em energia, conforto e sustentabilidade, uso de ferramentas de simulação, engenharia de valor, banco de dados e APO. Nesse processo, a fase do programa ganha destaque, incluindo a participação dos clientes, futuros usuários e os especialistas que devem estar envolvidos em todas as etapas de projeto e 
construção (FIGUEIREDO, 2009; NEGENDAHL, 2015).

A partir dos argumentos apresentados, evidencia-se a necessidade de estudos aprofundados sobre as etapas do processo de projeto consideradas ainda distantes do processo de referência indicado pela literatura (KOWALTOWKI; DELIBERADOR, 2014), sendo o programa arquitetônico uma dessas fases. O desafio é conduzir a etapa de programação visando a um produto que alimente o processo criativo de projeto e ainda controle, com a eficiência e a produtividade desejáveis, possíveis processos de projeto participativos.

\section{Programa arquitetônico escolar}

A reflexão sobre uma arquitetura escolar de qualidade inicia-se a partir da premissa de que o pensamento qualitativo e o planejamento devem começar antes do projeto propriamente dito. $\mathrm{O}$ planejamento da etapa de programação ganha importância à medida que afeta diretamente o processo de projeto (ZHANG; LIU, 2014). Muitas novas propostas de projetos escolares, pressionadas para economizar tempo e dinheiro, dispensam essa importante etapa. No entanto, cada solicitação para um novo projeto deveria ser entendida como um novo problema a ser resolvido, com características e demandas próprias a serem consideradas.

Ao se lidar com problemas de projeto com soluções previamente desenvolvidas, limitam-se as possibilidades criativas e impossibilita-se a participação dos usuários, ambos aspectos importantes quando se trata do ambiente escolar (TAYLOR; ENGGASS, 2008). Perde-se a oportunidade de refletir sobre antigos hábitos e de analisar sua eficácia ante as metodologias atuais. Além disso, os níveis qualitativos para o suporte correto dos ambientes escolares não são necessariamente encontrados em códigos ou especificações escolares (TAYLOR; ENGGASS, 2008), o que incrementa a importância da etapa do programa, em que devem ser reunidas as informações para a etapa do projeto.

O programa articula valores aos quais o arquiteto deverá responder em seu projeto (crenças, filosofias, ideologias, propósitos e ideias), que são a razão de ser do edifício, devendo, portanto, influenciar o modo como ele será projetado (HERSHBERGER, 1999). Nesse sentido, destacase a importância do processo participativo que permite a inclusão de aspectos típicos de cada localidade. Sabe-se da dificuldade de conduzir esse tipo de participação em função de razões econômicas, políticas e de organização social. Entretanto, ela vem sendo cada vez mais valorizada como uma maneira de, por um lado, enriquecer o processo criativo dos arquitetos e, por outro, aumentar o sentimento de pertencimento e inclusão da comunidade envolvida (DELIBERADOR, 2016).

$\mathrm{O}$ processo de projeto de escolas deve incluir alunos, pais, professores, funcionários, arquitetos, construtores, pedagogos, consultores de várias áreas e também os membros da comunidade, pois estes são considerados os agentes responsáveis por um novo empreendimento escolar (DUDEK, 2000; COMMISSION..., 2004). A falta de um programa arquitetônico completo pode prejudicar o resultado, inclusive porque, na realidade das escolas públicas brasileiras, não se dá prazo suficiente ao desenvolvimento do processo de modo a possibilitar que os profissionais busquem as informações faltantes e necessárias durante o próprio desenvolvimento do projeto. Nesse processo podem, portanto, faltar dados, necessidades e referências, o que pode resultar em uma solução final pouco amadurecida com relação aos parâmetros considerados essenciais à realidade específica que está sendo trabalhada.

\section{Agentes envolvidos no processo participativo}

$\mathrm{O}$ processo de projeto participativo é uma metodologia que se aplica a algumas etapas do processo de projeto arquitetônico e consiste na aplicação de atividades colaborativas em que futuros usuários (ou usuários "tipos") atuam oferecendo opiniões e pontos de vista que poderão influenciar as definições acerca do projeto final (LUCK, 2007; DEL RIO; IWATA; SANOFF, 2000).

A prática do processo participativo foi desenvolvida a partir dos anos 60. Entretanto, muitas vezes esse direito de participar acaba sendo limitado por pressões financeiras ou de tempo, o que inviabiliza uma atuação eficaz pelos participantes (REICH et al., 1996; SANDERS; BRANDT; BINDER, 2010). Deve-se frisar que, sem abrir mão do conhecimento técnico e científico do arquiteto, a atividade de projeto deve se constituir em um processo democrático e construtivo, por incluir a participação de futuros usuários para gerar espaços melhores, mais adequados e agradáveis (DEL RIO; IWATA; SANOFF, 2000).

$\mathrm{O}$ estímulo à participação desde as primeiras fases do projeto vem sendo uma tendência indicada pela literatura, uma vez que possibilita a adequação do próprio programa às necessidades de determinado público. A condução desses processos, de forma ética e de forma a realmente considerar os aspectos levantados pelos participantes, não é tarefa simples. 
Existem abordagens desses processos que apenas visam ao levantamento de algumas informações objetivas e ao apaziguamento dos envolvidos, que se constituem em abordagens que levam, na realidade, a uma pseudoparticipação, e não à participação genuína (WOOLNER, 2009), devendo, portanto, ser evitadas.

O objetivo primordial de um processo participativo é que se reconheçam mecanismos de aprendizado em duas diferentes vias: por um lado, futuros usuários que irão aprender mais sobre determinado projeto e sobre os eventos a ele relacionados, e, por outro, arquitetos e demais profissionais envolvidos que deverão aprender mais sobre a situação específica trazida pelos participantes (LUCK, 2007; WOOLNER, 2009).

A implementação desse tipo de processo demanda a aplicação de uma dinâmica de suporte por meio de ferramentas de apoio que busquem viabilizar a participação do coletivo, desde as etapas iniciais do processo de projeto. $\mathrm{O}$ grupo deve ser composto por todos os agentes capazes de contribuir com o planejamento de uma nova escola. A participação de alunos é fundamental, entretanto, dependendo da idade, devem participar em atividades planejadas exclusivamente para eles, com menor duração, especialmente no caso de crianças menores. Nesse sentido podem-se utilizar metodologias como "Poemas de Desejo", em que as crianças manifestam seus desejos para um novo ambiente escolar ou com "Walkthrough" ("passeio" em uma edificação escolar típica) especialmente desenvolvidos para serem realizados com crianças (SANOFF, 2001). Já para escolas de ensino médio, os alunos podem ser incluídos como integrantes dos processos participativos que utilizam técnicas como questionários, avaliação de satisfação, debates e outras metodologias.

Como se trata de diferentes usuários, com diferentes formações, culturas e personalidades, a condução adequada da discussão é essencial para o sucesso da realização do processo de projeto participativo, o que implica a necessidade de aplicação de metodologias específicas para cada grupo. A definição do grupo inclui o conhecimento de quem são os agentes que devem ser incluídos no processo. A seguir, uma breve descrição desses agentes da tipologia escolar para reflexão sobre como cada um pode contribuir para tornar o processo mais rico e completo.

\section{Especialistas diversos da área de educação: pedagogos, psicólogos,}

\section{sociólogos, representantes dos órgãos governamentais}

Aos educadores cabe a reflexão sobre quais atividades serão desenvolvidas nos espaços, quais as necessidades pedagógicas da escola e como essas se refletem na organização espacial do ambiente escolar. Esses profissionais trazem informações essenciais sobre as novas metodologias pedagógicas. Também se pode refletir sobre como o espaço pode influenciar o comportamento das crianças e jovens e quais são as configurações consideradas ideais para a aplicação dos conceitos e teorias pedagógicas no cotidiano escolar.

\section{Profissionais de projeto (arquitetos, engenheiros, paisagistas, urbanistas) e consultores de várias áreas (conforto ambiental, sustentabilidade, psicologia ambiental, saúde e segurança)}

Esses profissionais devem traduzir todas as informações conceituais definidas por suas áreas de atuação, assim como pela comunidade, para a constituição espacial do edifício escolar. Cabe a discussão da qualidade espacial e de sua capacidade de adaptação para os novos usos, fruto das novas modalidades pedagógicas e das mudanças sociais vividas. Embora nem sempre incluída nas discussões sobre a melhoria educacional, a qualidade espacial vem se mostrando cada vez mais relacionada à capacidade de aprendizado dos alunos (SANOFF, 2001; TARALLI, 2004; COMMISSION..., 2009). Os conceitos, desejos e necessidades devem ser expressos em termos das atividades a serem realizadas e, consequentemente, em espaços, traduzidos em áreas, índices de desempenho, características desejadas, etc. Os consultores têm papel essencial desde o início do processo de projeto, agindo para potencializar as decisões tomadas e indicando os melhores partidos para que todos os conceitos possam ser atendidos, respeitando as normas mínimas e também os índices desejáveis de conforto e sustentabilidade para os espaços. Quanto mais cedo esses consultores estiverem inseridos no processo de projeto através do projeto colaborativo, maiores serão as possibilidades de soluções que abranjam os diversos aspectos importantes de forma ideal.

\section{Comunidade escolar: alunos, pais, funcionários, professores, diretores e membros da vizinhança}

A inclusão da comunidade traz aos programadores uma visão essencial daqueles que vivem ou viverão a realidade do novo edifício escolar. Isso significa 
que esse grupo trará informações sobre como funciona aquele grupo de pessoas, quais são suas necessidades reais e também seus desejos. Todos esses agentes participam ativamente do dia a dia escolar e possuem características bastante peculiares, que devem fazer parte do programa das escolas. Nesse sentido, alunos de diversas idades que serão atendidas pelo edifício escolar devem fazer parte do processo, ainda que para isso sejam necessárias metodologias adequadas, tais como jogos e outras dinâmicas. Os pais, por serem parte importante do cotidiano, devem participar trazendo um olhar relacionado com suas expectativas sobre o ambiente escolar. Além disso, funcionários diversos, incluindo professores, diretores, da área de manutenção, da cozinha, etc., têm contribuição essencial ao processo, dada sua experiência com o funcionamento e com a rotina da escola em seu todo. A comunidade do entorno é bastante impactada pelo projeto de novas escolas, devendo também fazer parte dessa discussão.

A organização da colaboração entre diferentes pessoas, com diferentes competências e interesses é um desafio aos arquitetos, que necessitam de sistemas específicos que ofereçam suporte a esse tipo de processo (BRANDT, 2006; SANDERS; BRANDT; BINDER, 2010). A inclusão desses agentes traz dificuldades relacionadas com as expectativas criadas, que nem sempre podem ser atendidas em sua totalidade. Assim, ferramentas de apoio à participação podem colaborar para direcionar as discussões e organizar as informações obtidas de modo a estarem sustentadas na realidade possível de ser obtida pelo projeto final. Nesse sentido, a seguir se apresenta a metodologia dos grupos focais que pode ser utilizada e uma ferramenta de apoio desenvolvida para a etapa do programa arquitetônico participativo.

\section{Método do grupo focal para o processo de projeto participativo}

Diversos são os métodos indicados pela literatura para a realização de processos participativos. Uma das metodologias indicadas são os grupos focais (VILLA; ORNSTEIN, 2016). Existem diversas definições para "grupo focal", mas, de modo geral, pode-se afirmar ser esta uma metodologia de investigação e coleta de dados adequada à pesquisa qualitativa (ELALI; PINHEIRO, 2016; KRUEGER; CASEY, 2000). É realizada a partir de entrevistas em grupo, mas não no sentido de alternarem-se perguntas dos pesquisadores com respostas dos entrevistados, mas sim focada na interação do grupo como um todo (PUCHTA; POTTER, 2006). A discussão deve ser conduzida em torno de tópicos sugeridos pelo pesquisador, que, geralmente, assume o papel de moderador da discussão. A marca do grupo focal é o uso explícito da interação do grupo com a intenção de produzir dados e insights que poderiam ser menos acessíveis sem a interação proposta por essa metodologia (MORGAN, 1997). Templeton (1994) destaca que os grupos focais são pequenas comunidades temporárias, formadas com o propósito de realizar descobertas em conjunto sobre determinado assunto.

O planejamento de um grupo focal inclui a definição sobre como serão coletados os dados, quais serão os instrumentos necessários, assim como a definição sobre como serão estruturados os grupos, incluindo o nível de interação do moderador. Também deve ser definido o tamanho de cada grupo e o número de sessões que deverão ser realizadas. Além do moderador, que conduz a discussão, deve-se contar com o observador, que faz as anotações e não deve interferir, para não misturar os papéis (MORGAN, 1997; GOMES; BARBOSA, 1999; KRUEGER; CASEY, 2000; FARBSTEIN; WENER; MCCUNN, 2016). Para garantir a eficiência de um grupo focal, sabe-se que ele deve abranger o maior número de temáticas relevantes ao assunto em questão e buscar os dados mais específicos possíveis. Muitas vezes os dados produzidos podem ser vagos caso as temáticas não sejam bem explicadas aos participantes (PUCHTA; POTTER, 2006). Também se deve buscar identificar os sentimentos dos participantes e considerar o contexto utilizado por eles para elaborar suas respostas, garantindo um grupo focal realmente efetivo (MORGAN, 1997).

O início da sessão deve ocorrer com a introdução do tópico de maneira direta e sem grandes aprofundamentos, para não direcionar a participação dos envolvidos. A seguir se apresentam as regras de trabalho, e o moderador descreve como deverá ser sua própria atuação durante a sessão. No caso de haver também um observador, que ficará responsável pela coleta dos dados e observação da interação dos envolvidos, a função dele também deve ser brevemente indicada. Deve-se apresentar a questão a ser discutida e algumas ideias iniciais que ajudem na discussão. O moderador deve seguir a orientação das questões previamente elaboradas e trabalhar para incentivar a participação de todos ao longo das discussões. Diferentemente de outras técnicas de reunião, seu objetivo é geralmente a sinergia entre as pessoas: quanto mais ideias surgirem, melhor.

A análise dos resultados não é tarefa fácil. Após cada sessão, os pesquisadores devem reunir as anotações do trabalho, os sumários e qualquer outro 
dado relevante para analisar tendências e padrões (GOMES; BARBOSA, 1999).

A utilização da metodologia participativa por meio do grupo focal foi utilizada nesta pesquisa como forma de testar a ferramenta desenvolvida, descrita mais adiante. A metodologia se mostrou adequada, especialmente por ajudar na organização das discussões realizadas nos testes, que incluíram grupos formados pelos diversos agentes envolvidos na prática escolar.

\section{Jogos como ferramentas de apoio ao processo de projeto participativo}

Os jogos são técnicas que podem ser utilizadas para apoiar o processo de projeto participativo e facilitar a decisão sobre as características indispensáveis a determinado projeto. Na prática, o programa é uma atividade cujo objetivo é desenvolver e avaliar diversas opções para a organização do espaço de um edifício e de seu entorno e descobrir relações entre funções e espaços, testando conceitos programáticos (PEÑA; PARSHALL, 2012). Os jogos podem ser usados de duas maneiras: por equipes compostas apenas por especialistas ou em processos de projeto participativos, que incluem futuros usuários nas etapas de programação e de concepção do projeto. Eles permitem que sejam estudadas ações de projeto e que se providencie um ambiente manipulável e bem definido (HABRAKEN; GROSS, 1987).

De forma geral, os jogos são descritos como atividades de competição, com regras específicas, em que a força, a técnica, o acaso ou uma combinação desses fatores atua para definir o vencedor. Eles possibilitam o isolamento de certos conceitos ou aspectos de determinado projeto para que sejam minuciosamente estudados (HABRAKEN; GROSS, 1987; BRANDT; MESSETER, 2004). No caso dos jogos como ferramentas de apoio ao processo de projeto, o objetivo não é obter um jogador vencedor, e sim tirar vantagem das diferentes habilidades e interesses dos participantes, sejam eles especialistas ou futuros usuários, estabelecendo diferentes cenários de projeto possíveis, simulados em um ambiente de jogo (BRANDT, 2006). Os critérios e os conjuntos de regras para a aplicação dos jogos, além de uma razoável compreensão dos objetivos por parte dos participantes, são aspectos essenciais para o sucesso das atividades (PEÑA; PARSHALL, 2012). Diversos são os tipos de jogos que a literatura apresenta como apoio aos processos de projeto, dependendo da etapa e dos objetivos que se pretende alcançar. Pode-se mencionar como exemplos o Workplace Game (DE BRUYNE; DE JONG, 2008), no qual a ideia é a discussão sobre propostas inovadoras para os ambientes de trabalho em escritório, e o "DCBA" (AALBERS; KONING; TEEUW, 2010), que é um método de avaliação e tomada de decisão sobre estratégias de sustentabilidade dos edifícios desenvolvido a partir de um jogo de cartas.

No caso da tipologia escolar brasileira, o apoio no formato de jogos ainda não é comum em processos de projeto, mesmo que possa se constituir em um suporte adequado à etapa de programação. A ferramenta de apoio desenvolvida nesta pesquisa estimula os debates dessa etapa, de forma a garantir maior qualidade das informações obtidas, assim como colaborar para a condução ética nos processos de projeto participativos (DELIBERADOR; KOWALTOWSKI, 2015). A ética no processo participativo é indispensável para que os compromissos firmados com os envolvidos estejam de acordo com as possibilidades reais do projeto e para que todos tenham voz e direito de expor suas opiniões. Para isso, acredita-se serem importantes novas metodologias apoiadas em ferramentas com imagens que traduzam os parâmetros previamente estudados. O objetivo é que tais parâmetros sejam facilmente compreendidos pelos participantes, assim como funcionem como indicadores aos próprios arquitetos já na fase de projeto, estimulando, em ambos os casos, reflexões aprofundadas sobre o ambiente escolar.

\section{Resultados}

\section{Baralho da Escola}

A criação de uma ferramenta no formato de um jogo foi definida a partir das vantagens apresentadas pela literatura e por ser um modelo bastante adequado para aplicação em processos participativos, como mencionado na metodologia. A ferramenta de apoio para o processo de projeto apresentada aqui é um jogo de cartas, no formato de um baralho, chamado Desembaralhando a Arquitetura Escolar (DELIBERADOR, 2016). Ele está dividido em quinze naipes, e cada um representa uma temática importante nas discussões participativas. $\mathrm{O}$ conteúdo dos naipes foi levantado na literatura, incluindo estudos nacionais e internacionais, que indicaram os temas e os parâmetros a serem discutidos. A definição das cartas de cada naipe, assim como a configuração delas foi baseada nos conceitos dos parâmetros de projeto (ALEXANDER; ISHIKAWA; SILVERSTEIN, 2013; NAIR; FIELDING; LACKNEY, 2009). A opção por trabalhar com parâmetros de projeto com base no trabalho desses autores justifica-se por se tratar de um de formato adequado para a concepção 
de conceitos de projeto, o que justifica sua utilização para o desenvolvimento de uma ferramenta de apoio à etapa de programa arquitetônico (LASEAU, 2001). Um parâmetro de projeto deve descrever um problema que se repete no ambiente e propor uma solução conceitual que pode ser utilizada diversas vezes, sem resultar na mesma solução física (ALEXANDER; ISHIKAWA; SILVERSTEIN, 2013; WALDEN, 2015). Parâmetros não implicam verdades absolutas, mas sim descrevem um conjunto de relações que respondem a dada situação ou circunstância e que, por sua natureza, estão em constante mudança (WALDEN, 2015). A informação básica de um parâmetro inclui uma necessidade programática e um contexto, uma afirmação concisa verbal e gráfica de uma possível resposta ao problema e uma descrição mais detalhada da proposta ou discussão do parâmetro, que pode ser opcional.

Os naipes que compõem o jogo estão apresentados no Quadro 1. Um exemplo de naipe do jogo pode ser visualizado na Figura 1. O desenvolvimento completo da ferramenta, com a justificativa da escolha dos naipes e dos parâmetros de projeto, pode ser conhecido em Deliberador (2016). Optouse aqui por apresentar de forma resumida a versão final do jogo, pois o foco deste artigo é a discussão sobre a aplicação do jogo com foco na participação dos diversos agentes para a etapa de programação.

\section{Aplicação do Baralho da Escola através do grupo focal}

A ferramenta do jogo de cartas Baralho da Escola foi aplicada diversas vezes como teste para orientar as adaptações necessárias. Para a aplicação do projeto participativo, focado na inclusão dos diversos agentes, o método escolhido foi a realização de um workshop no formato de um grupo focal, que simulou um processo de projeto participativo. A preparação desse grupo focal incluiu a fase de planejamento, na qual se definiram suas características, como duração, número e tipo de participantes, atuação da mediadora, etc. Em termos gerais, planejou-se um período de trabalho de três horas e meia aproximadamente para o grupo focal. A formação deveria incluir a maior variedade possível de agentes, desde os relacionados à equipe de projeto (arquitetos, engenheiros, construtores, etc.) até aqueles da área de pedagogia e os usuáriostipo (pais, alunos, professores, diretores).

O grupo focal foi criado com o objetivo de simular a programação de uma escola pública de ensino fundamental I e II. Esse grupo focal foi formado por duas professoras e uma diretora de escolas públicas, uma pedagoga (professora universitária especialista em políticas públicas na educação), um pai de aluno de escola pública, um engenheiro de obra que trabalha em empreiteira que mantém contratos de projetos escolares públicos da FDE e um arquiteto. Não foram incluídos alunos, uma vez que a escola em questão se destinava a um público de crianças menores, cuja participação deve ser considerada por meio de outras metodologias. Além disso, o grupo focal ainda incluía um observador e um mediador da discussão (Figuras 2 e 3). A mediadora não necessitou de treinamento prévio, pois a função foi exercida pela própria pesquisadora. $\mathrm{O}$ observador e o arquiteto que conduziu a discussão foram informados previamente para que conhecessem o conteúdo do jogo e pudessem conduzir o grupo focal adequadamente.

\section{Quadro 1 - Naipes do jogo}

\begin{tabular}{|l|l|l|l|}
\hline Naipe 1 & Aspectos pedagógicos & Naipe 9 & Espaços de serviços dos alunos \\
\hline Naipe 2 & Modalidades de ensino & Naipe 10 & Áreas sociais \\
\hline Naipe 3 & Público-alvo & Naipe 11 & Circulação \\
\hline Naipe 4 & Inserção urbana & Naipe 12 & Conforto ambiental \\
\hline Naipe 5 & Espaços de ensino & Naipe 13 & Conceitos \\
\hline Naipe 6 & O pátio escolar & Naipe 14 & Psicologia ambiental \\
\hline Naipe 7 & Ambientes especiais & Naipe 15 & Aspectos comportamentais típicos do ambiente escolar \\
\hline Naipe 8 & Ambientes de apoio & \multicolumn{3}{|l|}{} \\
\hline
\end{tabular}




\section{Figura 1 - Exemplo de cartas de um naipe do jogo “Desembaralhando a Arquitetura Escolar"}
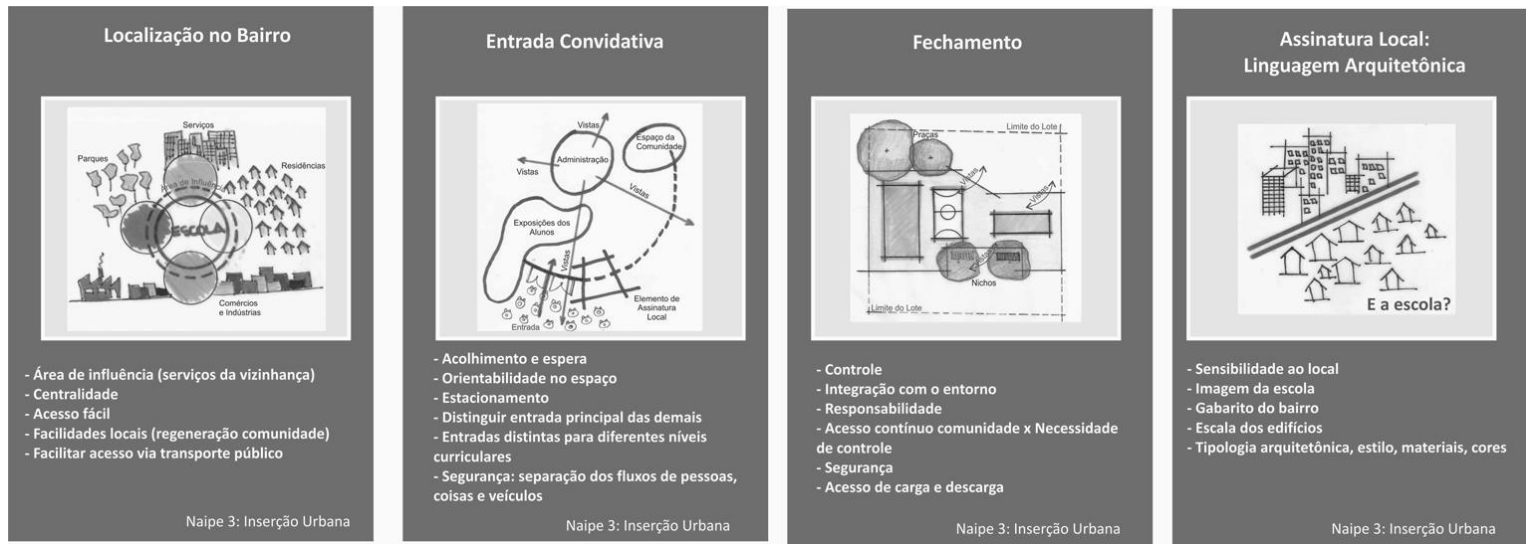

Figura 2 - Grupo focal em andamento 1

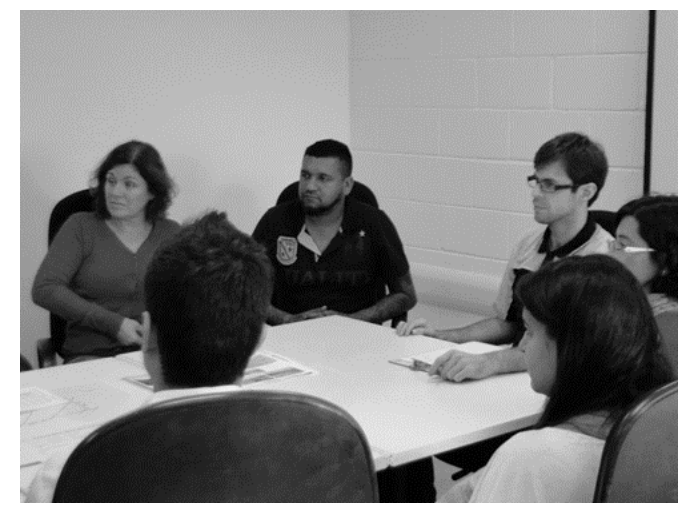

Figura 3 - Grupo focal em andamento 2

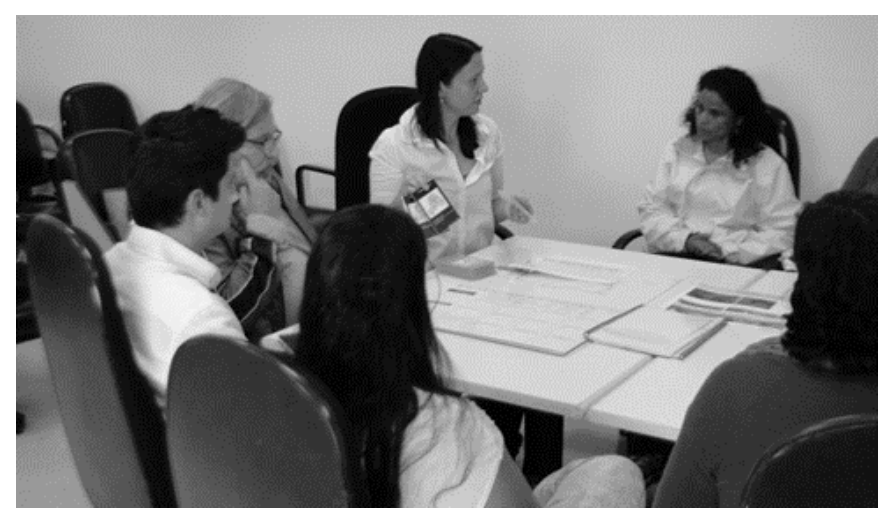

Para início dos trabalhos, a pesquisadora (aqui chamada de mediadora) iniciou o grupo focal descrevendo o local que serviria de referência para a simulação de um projeto de escola pública. A escolha do local foi feita com o critério de ser uma área onde exista um projeto escolar público, em bairro periférico e situação semelhante à da maioria dos processos de projeto de escolas públicas. O pai e a diretora presentes manifestaram que conheciam o local escolhido para a implantação do projeto.

Foi destacado pela mediadora que o projeto deveria ser de uma escola pública, de ensino fundamental I e II, uma vez que nem todas as escolas públicas dos estados ou municípios são separadas por fase única, com pedagogia livre a ser escolhida pelo grupo. A escola deveria atender 500 alunos em período integral. O grupo iniciou a discussão com a escolha da pedagogia, indicada como alternativa, mas não se especificou qual, pois se desejava uma mistura de conceitos que resultassem em uma proposta inovadora. Definiu-se que todos os parâmetros do naipe 2 (Modalidades de Ensino: Ensino ao Redor de uma Figura Central; Ensino Individual; Ensino 
por Projetos; e Ensino Informal) deveriam ser considerados no novo projeto.

Os demais naipes do jogo de cartas foram brevemente apresentados, assim como os parâmetros que os representavam. Naipes e parâmetros foram discutidos com ampla participação dos agentes envolvidos, especialmente uma interação clara entre o arquiteto e o grupo da área da educação. Todos os naipes despertaram o interesse dos participantes, tendo havido ampla discussão, sem que se possa destacar quanto a esse aspecto qualquer deles. $\mathrm{O}$ arquiteto se incumbiu de explicar questões espaciais e a implicação de algumas decisões para o projeto como um todo. Os pedagogos, por sua vez, esforçaram-se para definir os conceitos importantes do projeto e explicar como as metodologias pedagógicas deveriam ser aplicadas para potencializar as ações de ensino e aprendizagem do ambiente escolar. Exemplos de tabuleiros preenchidos, após a sessão do grupo focal, encontram-se nas Figuras 4 e 5.

Figura 4 - Tabuleiro I - preenchido na simulação do processo participativo (Naipes 1, 2, 3 e 4)

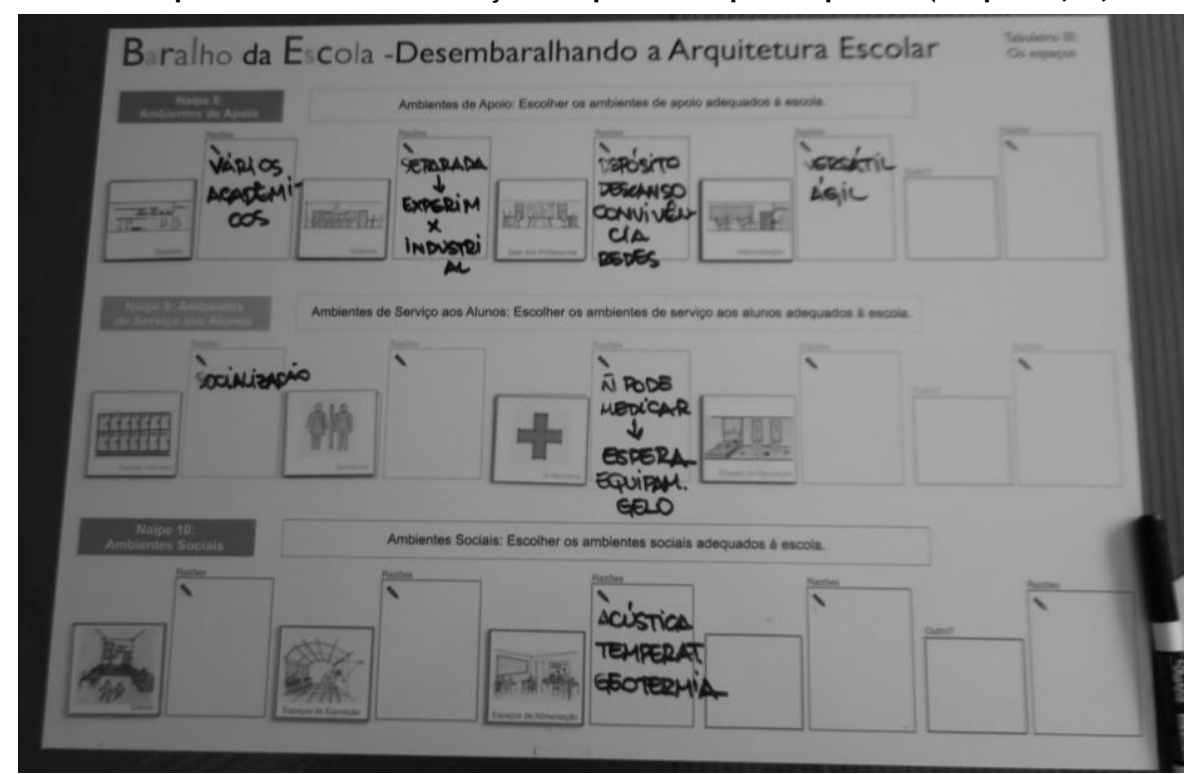

Figura 5 - Tabuleiro III - Os espaços - preenchido na simulação do processo participativo (Naipes 8, 9 e 10)

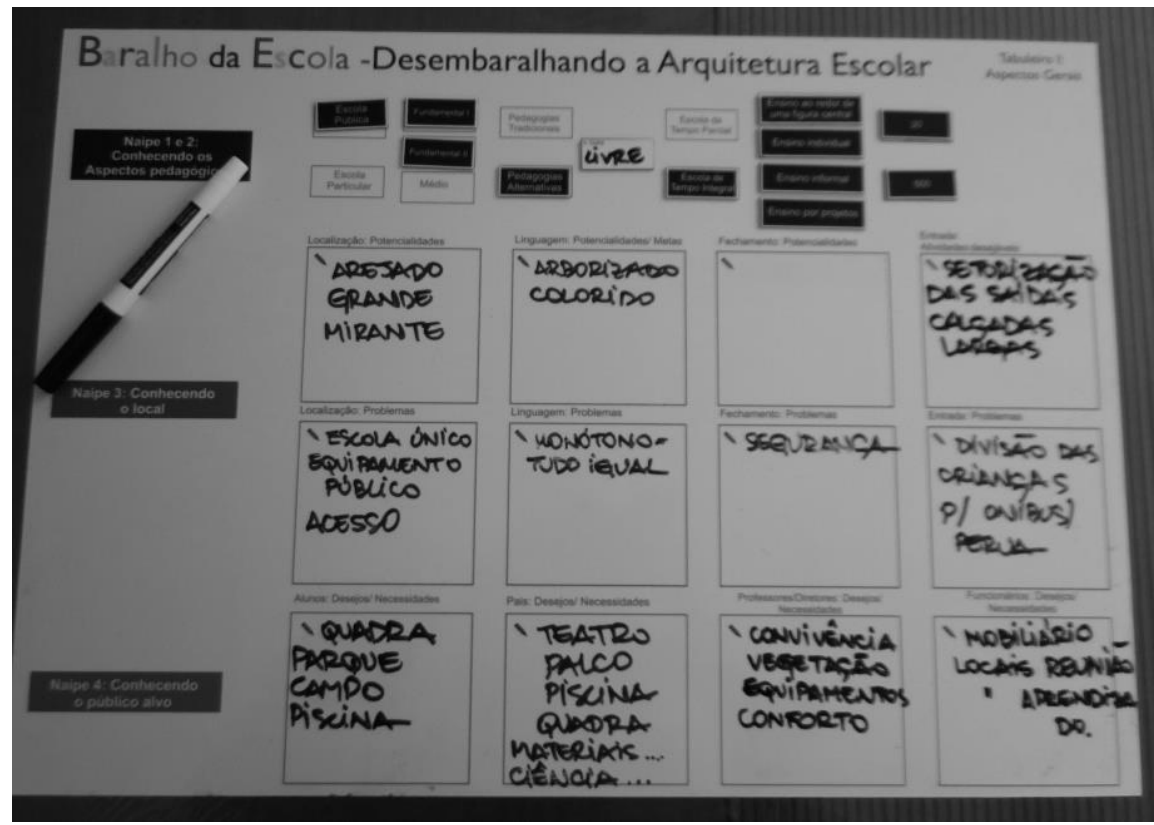




\section{Avaliação da participação dos agentes do grupo focal}

Após o encerramento do grupo focal, que durou aproximadamente três horas e meia, solicitou-se aos participantes a realização da avaliação do jogo. A avaliação geral de todos foi muito positiva. Questionou-se se os processos participativos poderiam colaborar com a melhoria da qualidade dos edifícios escolares, e 100\% dos participantes responderam que sim. Comentários muito interessantes completaram as respostas: "A interação entre os diversos tipos de profissionais (projetistas, professor, diretor, gestor da obra) faz com que todos os pontos sejam vistos por cada ângulo em particular, identificando necessidades que o projetista sozinho poderia não pensar" e "É muito importante a troca de ideias. Foi possível perceber como cada 'ator' enxerga a escola de maneira diferente. Somando cada experiência, com certeza a escola seria melhor".

Os depoimentos e a aderência dos integrantes desse grupo focal demonstram que a participação nesse processo simulado funcionou no sentido de alertar sobre como são diferentes as visões, mas, de outro lado, como todas elas são importantes ao se pensar um projeto escolar de maior qualidade. Com relação à necessidade de ferramentas de apoio, o grupo mostrou-se bastante favorável à criação de suportes aos processos participativos. Um participante destacou que as ferramentas eram importantes uma vez que "a participação sem planejamento pode perder o foco ou objetivo, importantes para atingir um resultado exequível e condizente com a realidade. $\mathrm{O}$ jogo direciona o grupo diversificado para um objetivo, sem ignorar as várias perspectivas". Outro destacou que "[...] o jogo favoreceu a reflexão. A situação de jogar colocou todos em igualdade, favorecendo a colaboração e a troca de experiências de todos os envolvidos".

Desse modo, constatou-se que a ferramenta cumpre com seu objetivo inicial, de estimular os debates e incentivar a participação dos diversos agentes. $\mathrm{O}$ grupo da área de educação incumbiu-se de apresentar e discutir questões relativas às metodologias pedagógicas e também da rotina escolar. Arquitetos e engenheiros manifestaram-se traduzindo tais questões para o ambiente construído escolar. Funcionários e professores preocuparam-se em adequar tais ideias à rotina escolar, que eles conhecem na plenitude. E, por fim, membros da comunidade apresentaram desejos e necessidades práticas das pessoas que receberiam a futura escola.

\section{Elaboração do programa arquitetônico a partir das informações do grupo focal}

A sessão do grupo focal não encerra em si a elaboração do programa arquitetônico. Ela é, em verdade, uma etapa na qual os profissionais obtêm mais dados para tornar o programa mais completo, rico e principalmente em acordo com os reais desejos e necessidades da comunidade que irá receber esse novo projeto. Nesse sentido, após a sessão participativa, os agentes que compõem o grupo "profissionais de projeto" devem se reunir para a etapa de condensação das informações obtidas no grupo focal e para a elaboração do documento do programa arquitetônico, geralmente coordenados pelo arquiteto responsável. No caso do teste realizado pela pesquisa, em razão da indisponibilidade circunstancial do arquiteto que coordenou a sessão, o programa foi realizado pela equipe de pesquisadores, que, com o documento pronto, apresentou-o ao arquiteto para validação. $\mathrm{O}$ arquiteto validou o documento e afirmou que certamente representa as discussões realizadas na sessão do grupo focal e configura-se como importante documento de suporte para o processo de projeto.

A elaboração desse documento foi feita com fichas desenvolvidas a partir do Problem Seeking (PEÑA; PARSHALL, 2012), que são parte do manual de instruções do jogo, disponível em Deliberador (2016). O programa completo foi elaborado com base nas discussões documentadas pelas imagens do tabuleiro realizadas após o grupo focal. Exemplos desse material podem ser vistos na Figura 6.

Observou-se que diretrizes de projeto foram traçadas a partir de questões levantadas no grupo focal. $\mathrm{O}$ atendimento das diversas modalidades de ensino do naipe 2, por exemplo, surgiu em razão da ampla discussão sobre sua importância pelo grupo da área de educação. Por outro lado, a tradução dos ambientes onde elas poderiam aparecer vem como resposta do arquiteto a essas discussões, que deve ser posteriormente validada pelos pedagogos e professores. Questões problemáticas da rotina escolar, como fechamentos, acessos e entrada, que haviam sido amplamente discutidas, aparecem com destaque no programa arquitetônico, o que sugere que seriam adequadamente consideradas na etapa seguinte de projeto. 
Figura 6 - Exemplos da compilação do programa arquitetônico

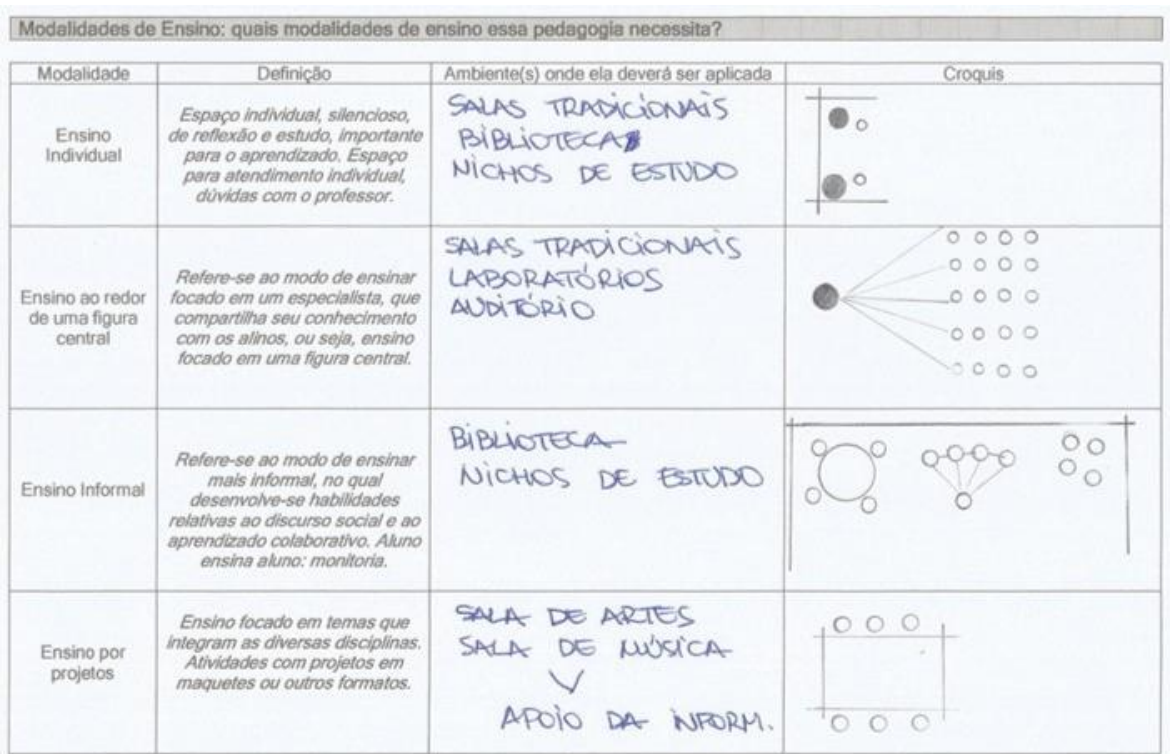

Inserção Urbana

\begin{tabular}{|c|c|c|c|}
\hline & Metas & $\begin{array}{l}\text { Identificar os problemas/potencialidades } \\
\text { do local de implantaçâo do projeto }\end{array}$ & $\begin{array}{l}\text { Qual a soluçăo arquitetônica para os } \\
\text { problemas e potencialidades do local? }\end{array}$ \\
\hline $\begin{array}{l}\text { Localização no } \\
\text { Bairro }\end{array}$ & $\begin{array}{l}\text { *VLORIZAR O } \\
\text { LOCAL DA ESCOA } \\
\text { ATRAVÉS DE UM } \\
\text { PROGPAMA AMPLIA- } \\
\text { DO COM ATIVIDA- } \\
\text { DES DE LAzER. }\end{array}$ & 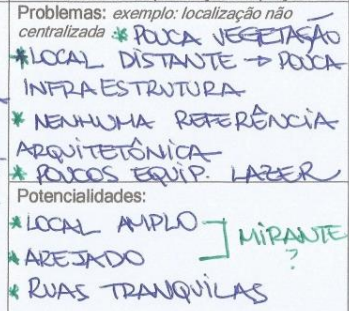 & $\begin{array}{l}\text { Exemplo: criaçáo de acesso próximo ao } \\
\text { transporte, presença de equipamentos } \\
\text { públicos como bancos, praças, arborização. } \\
\text { * PROGPANAA AMPLIADO } \\
\downarrow \\
\text { EQviPAMUENTOS DE } \\
\text { LAZER } \\
\text { * CRIACẼO DE PPASAS } \\
\text { COM EQUIPAMENTOS } \\
\text { * ARBORIZASATO }\end{array}$ \\
\hline
\end{tabular}

\begin{tabular}{|c|c|c|c|}
\hline \multirow[b]{2}{*}{ Assinatura Local } & Metas & $\begin{array}{l}\text { Identificar os problemas do local de } \\
\text { implantaçăo do projeto e verificar a } \\
\text { possibilidade de aplicação das metas }\end{array}$ & $\begin{array}{l}\text { Identificar as potencialidades do local } \\
\text { existente }\end{array}$ \\
\hline & $\begin{array}{l}\text { *Criar uma refe- } \\
\text { rêcia arquitetó } \\
\text { nica ao local } \\
\text { *edificio que }\end{array}$ & $\begin{array}{l}\text { * MONótano } \\
\text { * ARquItetura do } \\
\text { ENTORNO PADRONIzA } \\
\text { DA }\end{array}$ & $\begin{array}{l}\text { * CRIACATO DE UM } \\
\text { MIRANTE } \rightarrow \text { VAZIO } \\
\text { URBANO }\end{array}$ \\
\hline \multicolumn{4}{|c|}{ ENSINA } \\
\hline & Metas & Materiais possiveis & Indicadores de Avaliação \\
\hline Fechamento & $\begin{array}{l}\text { *OFERECER SEGU- } \\
\text { RANGA ÁS CRIAN } \\
\text { CAS, SEM A } \\
\text { ESCOLA PAPECER } \\
\text { UM PRESIDIO }\end{array}$ & 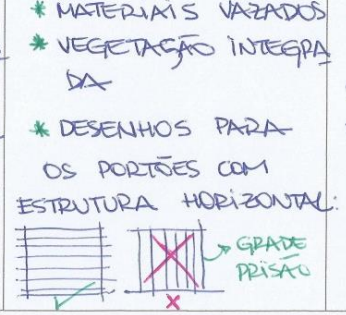 & $\begin{array}{l}\text { * garante-ge a } \\
\text { seguranga fisica } \\
\text { das criansas sem } \\
\text { parecer um presidio? } \\
\text { * nát tem grades? }\end{array}$ \\
\hline
\end{tabular}

\begin{tabular}{|c|c|c|c|}
\hline & Metas & Atividades para esse espaço & Possivel layout \\
\hline $\begin{array}{c}\text { Entrada } \\
\text { Convidativa }\end{array}$ & $\begin{array}{l}\text {-organizar a entra- } \\
\text { da e saida das } \\
\text { criangas setoriza- } \\
\text { das de acordo q } \\
\text { o meio de trans- } \\
\text { porte } \\
\text { * acolher } \\
\text { * Ser bonita }\end{array}$ & $\begin{array}{l}\text { * receber as cpianga } \\
\text { organizapanente } \\
\text { * esperar aos pais }\end{array}$ & 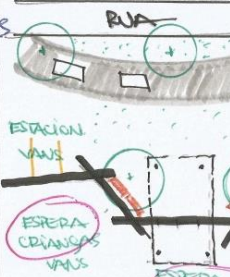 \\
\hline
\end{tabular}


Com o programa arquitetônico elaborado e o levantamento das questões acima, agendou-se uma nova reunião com a equipe de projeto que havia participado da sessão do grupo focal para que o programa fosse analisado. A avaliação foi favorável por se acreditar que as fichas sintetizam as discussões ocorridas no grupo focal. No entanto, questionou-se como se criam "compromissos" com o grupo participante para garantir que os desejos solicitados na sessão participativa se mantenham ao longo do processo, sem mudanças radicais. Esclareceu-se que geralmente esses processos não se resumem a uma única reunião. Sugere-se que, após a sistematização do programa, uma nova reunião seja feita para verificar com os participantes se todas as questões foram adequadamente compreendidas e tratadas. Esse momento pode também ser utilizado para firmar as metas traçadas para o desenvolvimento do projeto arquitetônico.

\section{Conclusões}

O jogo de cartas Baralho da Escola Desembaralhando a Arquitetura Escolar possibilitou a criação de um novo método de realização de um processo de projeto participativo, por meio da utilização de um jogo com o objetivo de fundamentar a fase de programa arquitetônico de projetos de novas escolas. A realização desse tipo de processo, que inclui diversos agentes do processo de projeto escolar, garante que as várias vozes sejam ouvidas e que haja um novo olhar sobre o edifício a ser elaborado.

A definição dessa ferramenta como um jogo confirmou as vantagens que a literatura havia indicado, ao favorecer a participação dos agentes. Além dos depoimentos colhidos na última sessão do grupo focal, na qual a maioria dos participantes manifestou-se favorável à utilização desse tipo de ferramenta, durante todas as aplicações observou-se que o formato possibilitava maior engajamento e interação entre os envolvidos (BRANDT; MESSETER, 2004; BRANDT, 2006). Além disso, estimulava a participação de todos com debates construtivos sobre a tipologia escolar, incentivando a reflexão sobre as necessárias mudanças espaciais em conjunto com as alterações pedagógicas. O jogo possibilitou, em todas as sessões, a criação de uma atmosfera divertida e favorável à criatividade, ainda que houvesse momentos difíceis de se obter consenso. A utilização do grupo focal como método de organização da aplicação do jogo também se mostrou muito adequada às sessões participativas. A figura do mediador e do observador é essencial para $\mathrm{o}$ andamento dos trabalhos $\mathrm{e}$ para a documentação das informações relevantes de cada uma das sessões.
O apoio do processo participativo com ferramentas, como o jogo criado nesta pesquisa, é essencial: os resultados demonstraram a relevância de incluir os agentes no processo, mas também indicaram as dificuldades de condução do processo participativo, que lida com diversas personalidades, com interesses e formação diferentes. Nesse sentido, o jogo se mostrou muito útil: ele estrutura as reflexões e induz um debate mais aprofundado e baseado em parâmetros de qualidade para o projeto. Também contribui para aproximar o programa das novas escolas e a realidade em que serão construídas.

$\mathrm{O}$ jogo se mostrou uma ferramenta que auxilia no gerenciamento de um grupo e pode ser utilizado de diversas maneiras, sempre buscando enriquecer o processo de projeto, vislumbrando a melhoria dos espaços escolares brasileiros. Sua utilização implicou uma nova etapa ao processo de projeto, investindo-se mais tempo na elaboração do programa arquitetônico, com, no mínimo, duas reuniões participativas: a primeira, no formato do workshop do grupo focal; e uma ou mais subsequentes para apresentar o programa final, verificar se está de acordo com as possibilidades e expectativas, e criar compromissos com a comunidade envolvida no processo.

O desenvolvimento do programa completo demonstrou como as questões levantadas no grupo focal se tornaram presentes e parte integrante das discussões, o que indica que seriam diretrizes projetuais importantes a serem seguidas nas etapas seguintes. Nesse sentido, a ferramenta mostrou-se capaz de agregar os diversos agentes em um processo de projeto participativo. Sua utilização possibilitou aprofundar a discussão da nova escola e seu impacto sobre a sociedade, incorporando questões ambientais, técnicas, sociais e econômicas ao programa e também dando voz aos diversos agentes de maneira produtiva. Entende-se que esse tipo de apoio é uma iniciativa na direção de buscar o desenvolvimento de meios que visem ampliar a qualidade do projeto e do espaço, avaliado a partir da satisfação dos usuários e da melhoria da educação, focados nos parâmetros específicos da arquitetura escolar.

\section{Referências}

AALBERS, K.; KONING, C.; TEEUW, P. Duurzame ideeën \& DCBA methodiek (Sustainable ideas \& DCBA Methodology). AEneas: Boxtel, 2010.

ALEXANDER, C.; ISHIKAWA, S.; SILVERSTEIN, M. Uma Linguagem de

Padrões. Porto Alegre: Bookman, 2013. 
AZEVEDO, G. A. N. Arquitetura Escolar e Educação: um modelo conceitual de abordagem interacionista. Rio de Janeiro: Ed. da UFRJ, 2002.

BARRETT, P. et al. The Impact of Classroom Design on Pupils' Learning: final results of a holistic, multi-level analysis. Building and Environment, v. 89, p. 118-133, 2015.

BRANDT, E. Designing Exploratory Design Games: a framework for participation in Participatory Design? In: CONFERENCE ON PARTICIPATORY DESIGN: EXPANDING BOUNDARIES IN DESIGN, 9., Trento, 2006 Proceedings... Trento, 2006.

BRANDT, E.; MESSETER, J. Facilitating Collaboration Through Design Games. In: CONFERENCE ON PARTICIPATORY DESIGN: ARTFUL INTEGRATION: INTERWEAVING MEDIA, MATERIALS AND PRACTICES, 8., Toronto, 2004. Proceedings... Toronto, 2004.

COMMISSION FOR ARCHITECTURE AND THE BUILT ENVIRONMENT. Being Involved in School Design. London, 2004.

COMMISSION FOR ARCHITECTURE AND THE BUILT ENVIRONMENT. Successful SCHOOL design. London, 2009

DE BRUYNE, E.; DE JONG, A. The Workplace Game: exploring end users' new behaviour. In: INTERNATIONAL CONFERENCE ON APPLIED HUMAN FACTORS AND ERGONOMICS, 2., Las Vegas, 2008. Proceedings... Las Vegas, 2008.

DEED, C.; LESKO, T. "Unwalling” the Classroom: teacher reaction and adaptation. Learning Environments Research, v. 18, n. 2, p. 217-231, 2015

DEL RIO, V.; IWATA, N.; SANOFF, H. Programação e Métodos Participativos Para o Projeto de Arquitetura: o caso do Colégio de Aplicação da UFRJ. In: NUTAU, 2000. Anais... São Paulo, 2000.

DELIBERADOR, M. S. O Processo de Projeto de Arquitetura Escolar no Estado de São Paulo: caracterização e possibilidades de intervenção. Campinas: Ed. da Unicamp, 2010.

DELIBERADOR, M. S. Parâmetros da Arquitetura Escolar e o Jogo de Cartas como Ferramenta de Apoio ao Desenvolvimento do Programa Arquitetônico. Campinas: Ed. da Unicamp, 2016.

DELIBERADOR, M. S.; KOWALTOWSKI, D. C. C. K. A Game as a Tool to Support the Architectural Program of Public School Building.
PARC Research in Architecture and Building Construction, v. 6, n. 2, p. 85-102, 2015.

DUDEK, M. Architecture of Schools: the new learning environments. Oxford: Architectural Press, Butterworth-Heinemann Ltd. Routledge, 2000.

ELALI, G. A.; PINHEIRO, J. Q. Analisando a Experiência do Habitar: algumas estratégias metodológicas. In: QUALIDADE Ambiental na Habitação: avaliação pós-ocupação. São Paulo, SP: Oficina de Textos, 2016.

ELALI, G. V. M. A. Ambientes para Educação: ocupação de edificações e na elaboração de diretrizes para projetos arquitetônicos na área. São Paulo: Ed. da USP, 2002.

FARBSTEIN, J.; WENER, R. E.; MCCUNN, L. J. Planning the Built Environment: programming. In: RESEARCH methods for environmental psychology. Oxford: John Wiley \& Sons, 2016.

FIGUEIREDO, F. Processo de Projeto Integrado Visando à Melhoria do Desempenho Ambiental de Edificações: levantamento, análise e comparação de dois estudos de caso. Campinas, 2009. Dissertação (Mestrado em Engenharia Civil) - Escola de Engenharia Civil, Universidade Estadual de Campinas, Campinas, 2009.

FUNARI, T. B.; KOWALTOWSKI, D. C. Arquitetura Escolar e Avaliação Pós-Ocupação. In: ENCONTRO NACIONAL DE TECNOLOGIA DO AMBIENTE CONSTRUÍDO, Maceió, 2005. Anais... Maceió, 2005.

GOMES, M. E. S.; BARBOSA, E. F. A Técnica de Grupos Focais Para Obtenção de Dados Qualitativos. Revista Educativa, p. 1-7, 1999.

HABRAKEN, H. J.; GROSS, M. D. Concept Design Games (books 1 and 2). Design Methodology Program. Department of Architecture. Cambridge: MIT Press, 1987.

HERSHBERGER, R. Architectural Programming and Predesign Manager. Routledge, 1999.

HIGGINS, S. et al. The impact of School Environments: a literature review. The Centre for Learning and Teaching, School of Education, Communication and Language Science, University of Newcastle, 2005.

HILLE, T. Modern Schools: a century of design for education. Oxford: John Wiley \& Sons, 2011.

KOWALTOWSKI, D. C. Arquitetura Escolar: o projeto do ambiente de ensino. São Paulo: Oficina de Textos, 2011. 
KOWALTOWSKI, D. C. C. K.; DELIBERADOR, M. S. Understanding School Design Processes. Journal of Design Research, v. 12, n. 4, p. 280307, 2014.

KRUEGER, R.; CASEY, M. A. Focus Groups: a practical guide for applied research. London: Sage, 2000.

LACKNEY, J. A. Educational Facilities: the impact and role of the physical environment of the school on teaching, learning and educational outcomes. Eric, 2000.

LASEAU, P. Graphic Thinking for Architects \& Designers. New Jersey: John Wiley \& Sons, 2001.

LUCK, R. Learning to Talk to Users in Participatory Design Situations. Design Studies, v. 28, n. 3, p. 217-242, 2007.

MORGAN, D. L. Focus Groups as Qualitative Research. London: Sage, 1997.

NAIR, P.; FIELDING, R.; LACKNEY, J. A. The Language of School Design: design patterns for 21st century schools. [S.1.]: Designshare, 2009.

NEGENDAHL, K. Building Performance Simulation in the Early Design Stage: an introduction to integrated dynamic models. Automation in Construction, v. 54, p. 39-53, 2015.

ORNSTEIN, S. W. Post-Occupancy Evaluation in Brazil. OECD/PEB Experts' Group Meetings on Evaluating Quality in Educational Facilities. In: OECD/PEB EXPERTS' GROUP MEETINGS ON EVALUATING QUALITY IN EDUCATIONAL FACILITIES, Paris, 2005. Proceedings... Paris, 2005.

PEÑA, W. M.; PARSHALL, S. A. Problem Seeking: an architectural programming primer. Oxford: John Wiley \& Sons, 2012.

PUCHTA, C.; POTTER, J. Focus Group Practice. London: Sage, 2006.

REICH, Y. et al. Varieties and Issues of Participation and Design. Design Studies, v. 17, n. 2, p. 165-180, 1996.

SANDERS, E. B.-N.; BRANDT, E.; BINDER, T. A Framework for Organizing the Tools and
Techniques of Participatory Design. In: BIENNIAL PARTICIPATORY DESIGN

CONFERENCE, 11., Sydney, 2010.

Proceedings... Sydney, 2010.

SANOFF, H. Schools Designed with Community Participation. ERIC, National Clearinghouse for Educacional Facilities, 2001.

TARALLI, C. H. Espaços de Leitura na Escola: salas de leitura/bibliotecas escolares. Boletim Salto para o Futuro, p. 31-39, 2004.

TAYLOR, A.; ENGASS, K. Linking Architecture and Education: sustainable design for learning environments. Albuquerque: UNM Press, 2008.

TEMPLETON, J. F. The Focus Group: a strategic guide to organizing, conducting and analyzing the focus group interview. [s.l.]: Irwi, 1994.

UCCI, M. et al. Indoor School Environments, Physical Activity, Sitting Behaviour and Pedagogy: a scoping review. Building Research \& Information, v. 43, n. 5, p. 566-581, 2015.

VILLA, S. B.; ORNSTEIN, S. W. Qualidade Ambiental na Habitação-Avaliação PósOcupação. São Paulo: Oficina de Textos, 2016.

WALDEN, R. Schools for the Future: design proposals from architectural psychology. [s.l.]: Springer, 2015.

WOOLNER, P. Building Schools for the Future Through a Participatory Design Process: exploring the issues and investigating ways forward.

BERA2009, p. 1-17, 2009.

WOOLNER, P. The Design of Learning Spaces. London: A\&C Black, 2010.

ZHANG, J.; LIU, J. N. The Summary and Analysis of Architectural Programming With the case. Advanced Materials Research, v. 1030, p. 2682-2685, 2014.

\section{Agradecimentos}

As autoras agradecem à Fundação de Amparo à Pesquisa do Estado de São Paulo (FAPESP) pelo financiamento da pesquisa que originou esse artigo (Fapesp 2013/00993-0 e 2017/05699-3). 
Marcella Savioli Deliberador

Faculdade de Engenharia Civil, Arquitetura e Urbanismo | Universidade Estadual de Campinas | Av. Albert Einstein, 951 |

Cidade Universitária Zeferino Vaz | Caixa Postal 6021 | Campinas - SP - Brasil | CEP 13083-852 | Tel.: (19) 99140-0230 |

E-mail: marcelladeliberador@yahoo.com.br

\section{Doris Catharine Cornelie Knatz Kowaltowski}

Faculdade de Engenharia Civil, Arquitetura e Urbanismo | Universidade Estadual de Campinas | Tel.: (19) $3521-2390$ |

E-mail: doris@fec.unicamp.br

\section{Revista Ambiente Construído}

Associação Nacional de Tecnologia do Ambiente Construído

Av. Osvaldo Aranha, $99-3^{\circ}$ andar, Centro

Porto Alegre - RS - Brasil

CEP $90035-190$

Telefone: +55 (51) 3308-4084

Fax: +55 (51) 3308-4054

www.seer.ufrgs.br/ambienteconstruido

E-mail: ambienteconstruido@ufrgs.br 


\section{Errata}

No artigo "Importância dos agentes para a arquitetura escolar: aplicação de jogo de apoio ao processo participativo", com número de DOI: <http://dx.doi.org/10.1590/s1678-86212018000200254>, publicado no periódico Ambiente Construído, 18(2):273-288.

Na página 273:

Onde se lia (filiação e autoria):

"Doris Catherine Cornelie Knatz Kowaltowski"

Leia-se:

"Doris Catharine Cornelie Knatz Kowaltowski"

Na página 288:

Onde se lia:

"Doris Catherine Cornelie Knatz Kowaltowski"

Leia-se:

"Doris Catharine Cornelie Knatz Kowaltowski" 